\title{
High Transverse Relaxivity and Anticancer Agent Loading/Release Characteristics of Porous Calcium Phosphate Coated Iron Oxide Nanoparticles
}

\author{
Baharak Divband ${ }^{1,2} \mathbb{( D )}$, Nahideh Gharehaghaji ${ }^{3} * \mathbb{1}$, Zahra Atashi 4 (1) \\ 1 Dental and Periodontal Research Center, Tabriz University of Medical Sciences, Tabriz, Iran; divband@tabrizu.ac.ir \\ (B.D.); \\ 2 Inorganic Chemistry Department, Chemistry Faculty, University of Tabriz, C.P. 51664, Tabriz, Iran \\ 3 Department of Radiology, Faculty of Paramedicine, Tabriz University of Medical Sciences, Tabriz, Iran; \\ gharehaghajin@tbzmed.ac.ir (N.G.); \\ 4 Department of Medical Physics, Faculty of Medicine, Tabriz University of Medical Sciences, Tabriz, Iran; \\ atashizahra913@gmail.com (Z.A.); \\ * Correspondence: gharehaghajin@tbzmed.ac.ir;
}

Scopus Author ID 16174661300

Received: 1.10.2020; Revised: 23.10.2020; Accepted: 24.10.2020; Published: 26.10.2020

\begin{abstract}
High relaxivity of MRI contrast agents leads to considerable contrast enhancement in the images and provides diagnostic accuracy. The purpose of the current study was to design a potential MRI contrast agent with a high relaxivity and investigate its curcumin loading/release property. To achieve this purpose, we synthesized the porous calcium phosphate coated iron oxide nanoparticles using a facile method and determined the physicochemical characteristics, cell compatibility effect, transverse relaxivity, and curcumin loading/release properties of the nanoparticles. The results indicated the spherical nanoparticles with a size of 10-20 nm. The nanoparticles demonstrated a superparamagnetic property and a high transverse relaxivity of $845.71 \mathrm{mM}^{-1} \mathrm{~S}^{-1}$. Although the porous calcium phosphate coated iron oxide nanoparticles were highly cytocompatible, the curcumin loaded nanoparticles showed a considerable effect on the bone marrow stem cells viability. In conclusion, the porous calcium phosphate coated iron oxide nanoparticles have the potential to introduce as a negative contrast agent of MRI with the ability of slow release of curcumin.
\end{abstract}

Keywords: transverse relaxivity; nanoparticles; iron oxide; porous calcium phosphate; anticancer agent.

(c) 2020 by the authors. This article is an open-access article distributed under the terms and conditions of the Creative Commons Attribution (CC BY) license (https://creativecommons.org/licenses/by/4.0/).

\section{Introduction}

The Iron oxide nanoparticles have a wide range of biomedical applications, including contrast-enhanced magnetic resonance imaging (MRI) [1], cancer treatment hyperthermia [2], perfusion imaging [3], and anticancer drug delivery [4]. The nanoparticles have a superparamagnetic property and enhance the contrast of MR images because of their capacity to change relaxation times of water protons under high magnetic fields. Although iron oxide nanoparticles affect both spin-lattice (T1) and spin-spin (T2) relaxation times, they appear as low signal intensity dark regions on the images due to their higher effect on shortening of T2 relaxation time and producing susceptibility artifact $[5,6]$. Therefore, the nanoparticles are considered as T2 or negative contrast agents of MRI. The capability of an MRI contrast material to enhance the contrast of MR images is specified by the term "relaxivity" (r). Relaxivity 
demonstrates changes in 1/T1 or 1/T2 relaxation rates as a function of magnetic ion concentration [7]. A higher relaxivity, a higher MRI contrast improvement. For iron oxide nanoparticles, transverse relaxivity ( $\mathrm{r} 2)$ is higher than that of longitudinal relaxivity ( $\mathrm{r} 1)$, indicating the property of a T2 contrast material of MRI. Iron oxide nanoparticles should be surface modified by using biocompatible coatings to prevent their toxic effect, agglomeration, and oxidation. Providing chemical stability and the possibility of binding anticancer drugs to nanoparticles are other roles of coating materials [8-12].

Hydroxyapatite with calcium phosphate porous structure is an inorganic bioactive and biocompatible material naturally found in bones and teeth $[13,14]$. Thanks to the biological, chemical and physical properties, hydroxyapatite, its composites, and nanosized forms are good candidates for various applications such as adsorbents for removal of water fluoride $[15,16]$, bone regeneration and bone tissue engineering [17-19], coating for dental implants [20,21], and orbital implants [22].

Hydroxyapatite nanoparticles have been synthesized using various methods [23-26]. Each synthesis method has its own processing properties and can lead to a different morphology [13]. Hydroxyapatite can be synthesized from natural [27-29] or chemical $[23,24,26]$ sources. Synthetic nano-hydroxyapatites are suitable for the coating of magnetic ions due to their biocompatibility, stability, and non-inflammatory properties [30]. Magnetic hydroxyapatite nanostructures have been used for different biomedical applications such as magnetic hyperthermia, drug, gene, and protein delivery [31,32], and MR imaging [26, 33-35].

The potential application of magnetized hydroxyapatite nanocrystallites synthesized by the wet-chemical precipitation method as a biodegradable MRI contrast material was investigated by Wu et al. [33]. Other researchers synthesized Fe-modified calcium deficient hydroxyapatite nanoparticles by ultrasonic-assisted precipitation method at low temperature. They showed the magnetic property of the nanoparticles using vibrating sample magnetometry and concluded that the nanoparticles could be used for MRI [34]. In another study, $\mathrm{Fe}_{3} \mathrm{O}_{4} @ \mathrm{HAp}$ core-shell nanoparticles were synthesized by a combination of the coprecipitation method with hydrothermal treatment at different temperatures. The researchers investigated the magnetic properties of the nanoparticles for different amounts of HAp and evaluated the dependence of the blocking temperature on the shell thickness by computer simulation. In addition, they studied the MRI properties of the nanoparticles and showed their capability as MRI contrast agents [26]. However, the r2 relaxivity of the nanostructures did not investigate in any of these studies. In another study, magnetic hydroxyapatite nanocomposite was synthesized using the hydrothermal method. They reported the $\mathrm{r} 2$ relaxivity of the nanocomposite and investigated the MCF-7 cells uptake of the curcumin loaded composite [35]. However, their nanocomposite was nanorod in shape, and the magnetite and hydroxyapatite formed two separate phases. Since for in vivo applications, the spherical shape of the nanostructures is an important factor for easy transfer of them in blood vessels; in the present study, we aimed to synthesize the spherical shape porous hydroxyapatite-coated iron oxide nanoparticles with a high $\mathrm{r} 2$ relaxivity for MRI and slow release of curcumin.

\section{Materials and Methods}

\subsection{Nanoparticles synthesis.}

$\mathrm{NH}_{4} \mathrm{OH}(25 \%)$ was added dropwise over 60 mins into the $30 \mathrm{ml}$ aqueous solution of $\mathrm{FeCl}_{2} .4 \mathrm{H}_{2} \mathrm{O}$ and $\mathrm{FeCl}_{3} .6 \mathrm{H}_{2} \mathrm{O}$ with a molar ratio of $2: 1$ using a pipe under constant mechanical 
stirrer (300 rpm) at $80^{\circ} \mathrm{C}$ and the final $\mathrm{pH}$ was 10 . The solution was heated up to $90^{\circ} \mathrm{C}$, and 0.1 $\mathrm{M}$ citric acid was added to it under $\mathrm{N}_{2}$ atmosphere; at last, the nanoparticles were washed with deionized water. In order to synthesis hydroxyapatite-coated $\mathrm{Fe}_{3} \mathrm{O}_{4}$ nanoparticles, an aqueous solution of $\mathrm{Ca}\left(\mathrm{NO}_{3}\right)_{2} .4 \mathrm{H}_{2} \mathrm{O}$ and $\left(\mathrm{NH}_{4}\right)_{2} \mathrm{HPO}_{4}$ at $\mathrm{pH}$ of 11 was prepared and gradually added to $50 \mathrm{ml}$ suspension of as-synthesized iron oxide nanoparticles. After the appearance of milky suspension, it was heated up to $90^{\circ} \mathrm{C}$ for $2 \mathrm{~h}$ under ultrasound and stayed overnight. The dark brown particles were washed several times up to reach a $\mathrm{pH}$ of 7 , then dried in a vacuum and calcinated at $400^{\circ} \mathrm{C}$ for $3 \mathrm{~h}$. The as-prepared hydroxyapatite-coated iron oxide nanoparticles were named MHAp.

\subsection{Physicochemical analysis tests.}

X-ray diffraction (XRD) pattern was obtained by the usage of a Philips diffractometer. Transmission electron microscopy (TEM) was carried out using a Zeiss LEO 912 Omega device. Vibrating sample magnetometry (VSM) was conducted by a magnetometer model 7400 under $-20000 \leq \mathrm{H} \leq+20000 \mathrm{G}$ field intensity at room temperature. The curve of the magnetization versus applied magnetic field was plotted to investigate the magnetic property of the nanoparticles.

\subsection{MTT assay.}

The cytotoxicity effect of the nanoparticles on bone marrow stem cells in passage 4 was investigated by MTT cell proliferation test according to the following steps:

1) Culturing the bone marrow stem cells in the plates with 96 wells $\left(13 \times 10^{3}\right.$ cells for each well) with $200 \mu \mathrm{L}$ of the culture media in each well at $37^{\circ} \mathrm{C}$ for $24 \mathrm{~h}$;

2) Division of the cells into four groups in triplicate: the control, MHAp nanoparticles, curcumin and curcumin loaded nanoparticles;

3) Elimination of the media and washing with a phosphate-buffered solution (PBS);

4) Measurement of the cellular proliferation by adding $50 \mu \mathrm{L}$ of $\mathrm{MTT}(3-(4,5-$ dimetylthiazol- 2-yl)-2, 5-diphenyl- trazolium bromide) and $150 \mu \mathrm{L}$ culture medium to each well;

5) Incubation of the cells at $37^{\circ} \mathrm{C}$ and $5 \% \mathrm{CO}_{2}$ for $24 \mathrm{~h}$;

6) Elimination of the media;

7) Adding $200 \mu \mathrm{L}$ dimethyl sulfoxide and $25 \mu \mathrm{L}$ Sorenson buffer;

8) Reading the absorbance using an ELISA plate reader at $570 \mathrm{~nm}$ wavelength;

\subsection{MRI study.}

A clinical MRI scanner (Siemens, AVANTO, Germany) with a magnetic field intensity of 1.5 Tesla was used to prepare the T2-weighted images. The samples of the nanoparticles with various concentrations of Fe ion in the agar matrix were put in the glass tubes and arranged in a water-filled glass phantom. In addition, one glass tube was filled with agar as zero concentration. A multi spin-echo sequence with 16 echo, TR: $3500 \mathrm{~ms}$, and TE: 15-240 ms was carried out to acquire the T2 images. The signal intensity of the samples was measured by a DicomWorks (1.3.5) software, and the T2 graphs were plotted using MATLAB software (R2016b version). The T2 relaxation times were extracted from the T2 curves and used for plotting the $\mathrm{r} 2$ relaxivity graph. 


\subsection{Curcumin loading and release.}

Curcumin was loaded on the MHAp by a soaking procedure. Briefly, $200 \mathrm{mg}$ of desired nanoparticles were mixed with curcumin solution in ethanol $(4 \mathrm{mg} / \mathrm{mL})$ and stirred for at least $48 \mathrm{~h}$ at room temperature. Then, the solution was centrifuged and dried at $60{ }^{\circ} \mathrm{C}$ overnight. The amount of curcumin on the nanoparticles was calculated considering the absorption of the supernatant at $\lambda=418 \mathrm{~nm}$ by UV-visible spectrophotometer (Jenway 6305) using the following formula:

Loading efficiency $(\%)=(($ Total drug - Unloaded drug $) /$ Total drug $) * 100$

For release investigation, $50 \mathrm{mg}$ of the as-prepared curcumin loaded MHAp nanoparticles were placed into a dialysis bag (cutoff $12 \mathrm{kDa}$ ) and put into $100 \mathrm{~mL}$ of phosphatebuffered saline (PBS) with $\mathrm{pH}$ of 7.4 under stirring at $37^{\circ} \mathrm{C}$. At the determined time intervals, the drug concentration in the dialysate was investigated by UV-Vis spectroscopy at $\lambda=418$ $\mathrm{nm}$.

\section{Results and Discussion}

\subsection{Physicochemical analysis tests.}

Figure 1 shows the XRD pattern of MHAp nanoparticles with the peaks related to the $\mathrm{Fe}_{3} \mathrm{O}_{4}$ and hydroxyapatite. The XRD analysis indicates the well-crystallized nanostructures. The findings are in agreement with Yusoff et al. study [36].

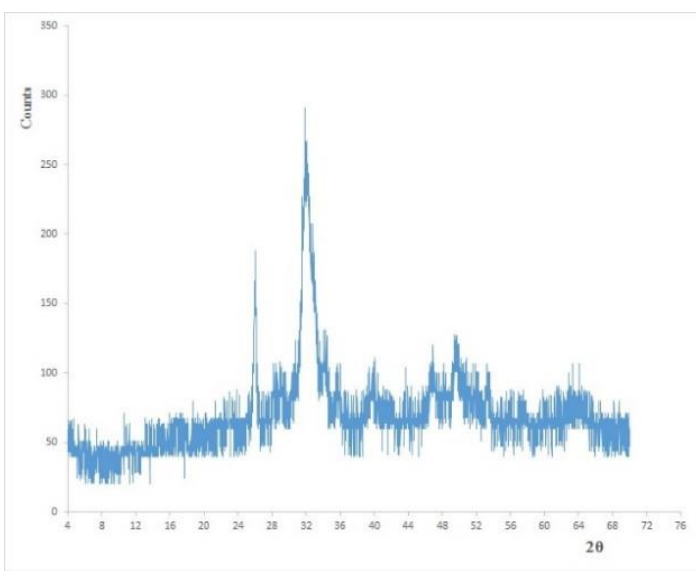

Figure 1. XRD pattern of MHAp nanoparticles.

TEM image demonstrates the spherical shape and 10-20 nm size of the nanoparticles (figure 2). The shape and size of the nanoparticles can provide easy transfer and long half-life of them in the blood circulation.

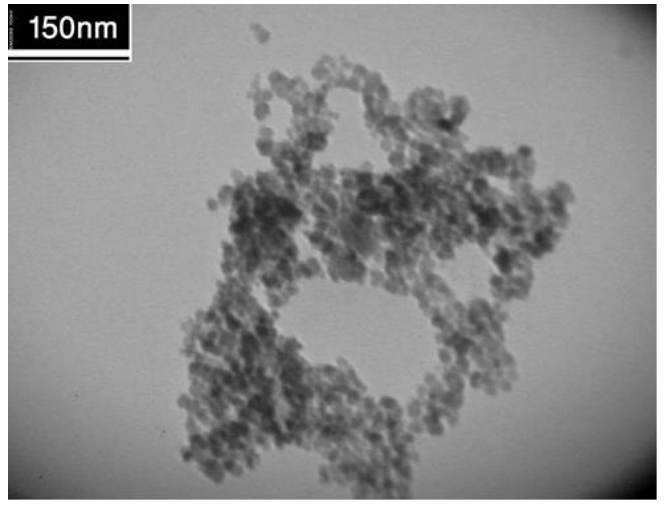

Figure 2. TEM image of MHAp nanoparticles. 
Figure 3 illustrates the VSM results of the nanoparticles. According to the figure, there is no remanent magnetization, coercivity, and hysteresis loop, indicating the superparamagnetic behavior of the nanoparticles.

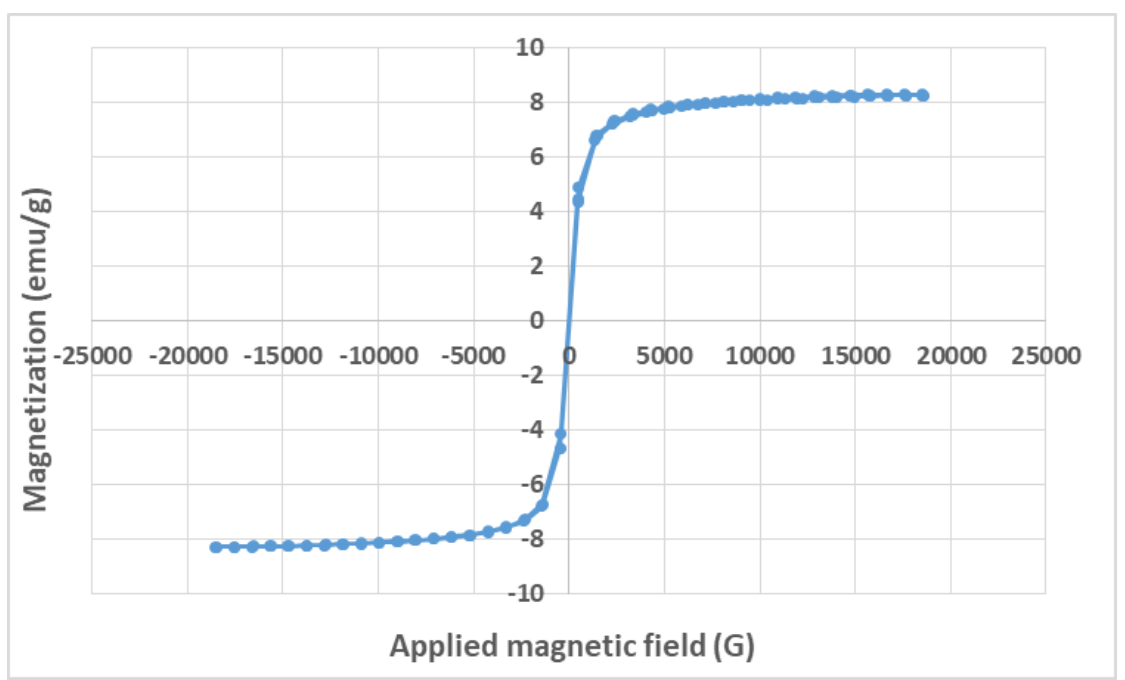

Figure 3. Magnetization curve of MHAp nanoparticles at room temperature.

\subsection{MTT assay.}

The results of the MTT assay for the control group, MHAp nanoparticles, curcumin, and curcumin loaded MHAp are seen in figure 4. MHAp nanoparticles showed high cell compatibility even more than the control group due to the biocompatibility of the hydroxyapatite coating. The cytocompatibility of the MHAp nanoparticles was increased, with the nanoparticles concentration increasing. The highest cell compatibility was obtained at the highest concentration $(0.4 \mathrm{mg} / \mathrm{ml})$ of MHAp nanoparticles. Curcumin was cytocompatible at the lowest concentration $(0.05 \mathrm{mg} / \mathrm{ml})$, and its compatibility was decreased with the concentration increasing.

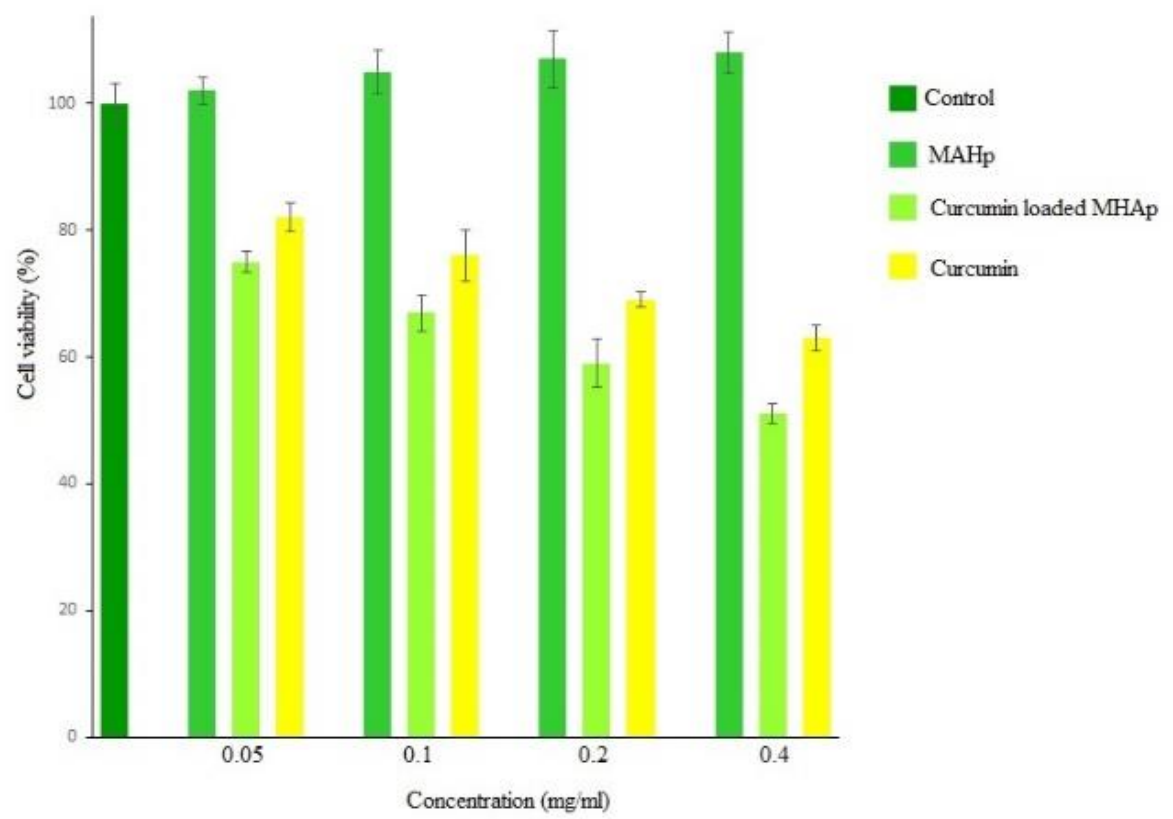

Figure 4. Bone marrow stem cells viability after $24 \mathrm{~h}$ incubation with various concentrations of MHAp nanoparticles, curcumin, and curcumin loaded MHAp. 
This finding indicates that at a concentration lower than $0.05 \mathrm{mg} / \mathrm{ml}$, the curcumin amount is not adequate to show effective cell killing. The lowest cytocompatibility was seen for curcumin loaded MHAp nanoparticles. For all concentrations, the cell compatibility of the curcumin loaded MHAp nanoparticles was less than $80 \%$. The cell-killing effect of curcumin loaded MHAp was increased in a concentration-dependent manner. Although curcumin is an anticancer agent, its effect on cell killing was less than curcumin loaded MHAp nanoparticles because of its hydrophobic property. On the other hand, the loading of curcumin to MHAp nanoparticles facilitates the access of the curcumin to the cells and enhances its cell-killing effect. Comparing the cell viability of MHAp nanoparticles with curcumin loaded MHAp shows considerable changes in the cytocompatibility of the nanoparticles, which converts highly cytocompatible MHAp nanoparticles to an effective cell killer, curcumin loaded MHAp nanoparticles. These findings also confirm the successful loading of the curcumin to MHAp nanoparticles.

\subsection{MRI.}

Figure 5 shows a sample of the MR images of the nanoparticles with different concentrations and related signal intensities. A significant decrease in the signal intensity of the samples was seen as the concentration of the nanoparticles was increased. Assuming the signal intensity at zero concentration is $100 \%$, the value of the signal intensity dramatically dropped to $61.10,29.89,20.03$, and $8.42 \%$ for the Fe concentrations of $0.014,0.028,0.042$, and $0.056 \mathrm{mM}$, respectively. This finding indicates a significant signal loss in the presence of the MHAp nanoparticles, which is as high as $91.58 \%$ for the highest concentration.

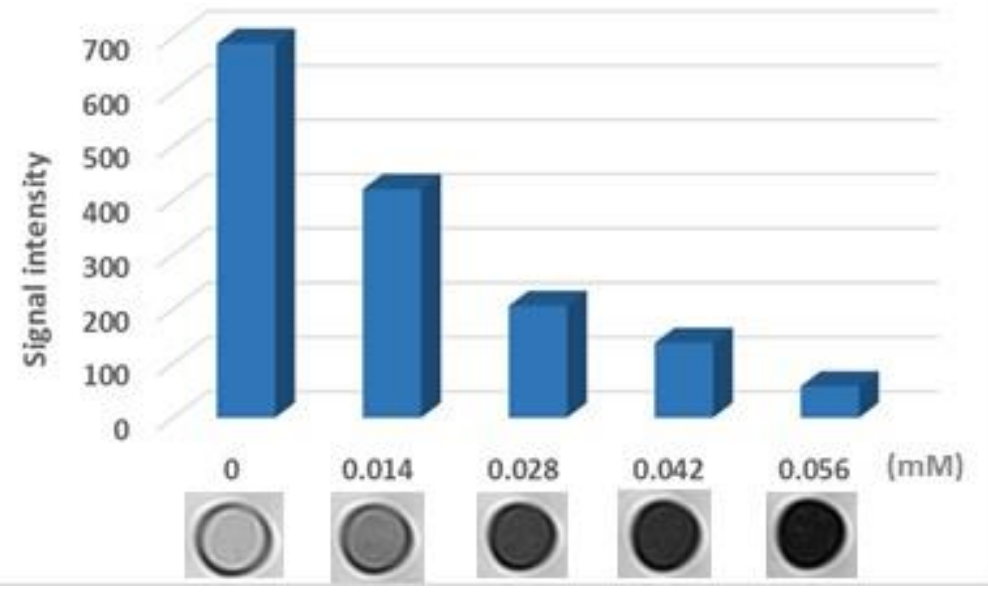

Figure 5. MR images of MHAp nanoparticles with different concentrations and related signal intensities.

Figure 6 illustrates the 1/T2 relaxation rate versus $\mathrm{Fe}^{3+}$ concentration graph with a high relaxivity value of $845.71 \mathrm{mM}^{-1} \mathrm{~S}^{-1}$. Iron oxide particles as magnetic cores create local inhomogeneities in the magnetic field. Although complete coverage of the iron oxide nanoparticles is done by hydroxyapatite coating, the porous structure of hydroxyapatite provides high access of the nanoparticles to the water protons. Therefore, the spin-spin interactions are accelerated, leading to a strong shortening in the $\mathrm{T} 2$ relaxation time. Consequently, a high $\mathrm{r} 2$ relaxivity has resulted, which indicates a high potential of the MHAp nanoparticles to use as a negative contrast agent of MRI. 


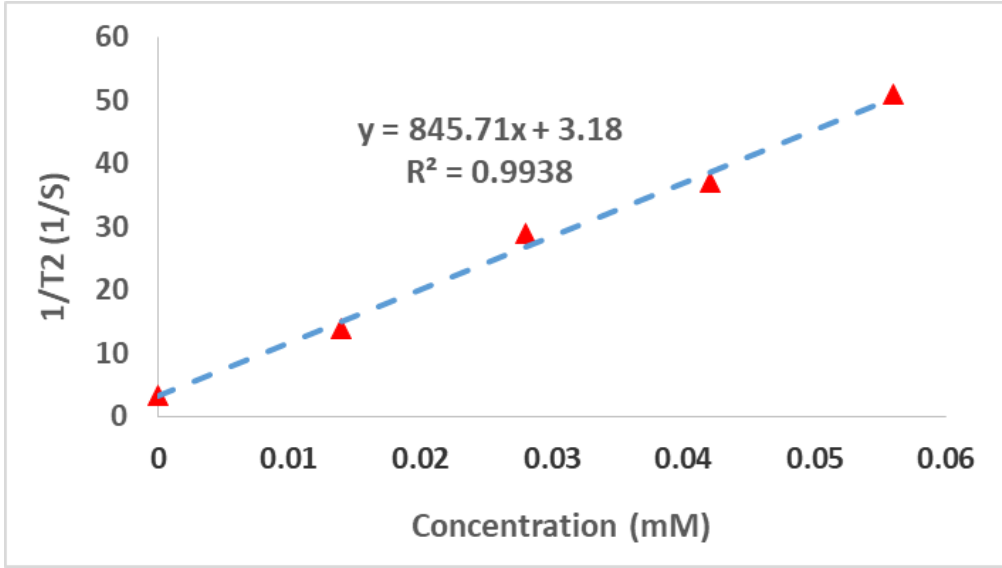

Figure 6. Relaxivity graph of MHAp nanoparticles.

The $\mathrm{r} 2$ relaxivity of MHAp nanoparticles in this study is seven times higher than that of the commercial T2 contrast agent of MRI, Endorem. In addition, it is much higher than that of the poly(N-vinyl pyrrolidone) (PVP)-grafted magnetite nanoparticles [37], the $\mathrm{Fe}_{3} \mathrm{O}_{4}$ nanoparticles with the coating of dimercaptosuccinic acid (DMSA) [38], and $\mathrm{Fe}_{3} \mathrm{O}_{4} @ \mathrm{Au}$ nanoparticles [39]. Differences in the $\mathrm{r} 2$ relaxivity of these studies related to the differences in the nanoparticles size, coating type, and thickness.

The spherical shape of the nanostructures is an important factor which provides easy transfer of them in blood circulation. In our study, the MHAp nanoparticles had a spherical shape, while in the Kermanian et al. study [35], the magnetic hydroxyapatite nanocomposite showed a nanorod morphology due to using cetyltrimethylammonium bromide (CTAB) as a surfactant. In addition, in their study, the magnetite and hydroxyapatite formed two separate phases.

\subsection{Curcumin loading and release.}

The extent of curcumin loaded on the MHAp nanoparticles was determined to be $89.6 \%$ after $48 \mathrm{~h}$. The release profiles of curcumin from curcumin loaded MHAp nanoparticles at $\mathrm{pH}$ of 7.4 demonstrated that the maximum attainable amount of the drug release at $\mathrm{pH}$ of 7.4 was about $68 \%$ and $81 \%$ of the loaded amount, which was achieved in 120 and $240 \mathrm{~h}$, respectively.

\section{Conclusions}

In this study, porous calcium phosphate (hydroxyapatite) coated iron oxide nanoparticles (MHAp) were synthesized successfully using a facile one-pot synthesis method. The nanoparticles showed a spherical shape, 10-20 nm size, superparamagnetic property, and high cell compatibility. These properties, along with the high transverse relaxivity of the nanoparticles, make them an appropriate candidate for MR imaging purposes. The curcumin loaded nanoparticles showed a considerable effect on the bone marrow stem cells viability in MTT assay. The findings confirm the successful curcumin loading and potential of the nanoparticles for the slow release of the anticancer agent. Therefore, the nanoparticles have the potential to use as a negative contrast agent for MRI with suitable loading/release of curcumin. Although this study was performed in vitro, according to the shape, size, MRI, and curcumin loading/release characteristics of the nanoparticles, the nanostructure can be appropriate for future in vivo studies in an animal model. 


\section{Funding}

This research was financially supported by the Paramedical Faculty of Tabriz, University of Medical Sciences, grant number 1397.169.

\section{Acknowledgments}

The authors would like to thank the Faculty of Paramedicine, Tabriz University of Medical Sciences, for supporting this research.

\section{Conflicts of Interest}

The authors declare no conflict of interest.

\section{References}

1. Khmara, I.; Strbak, O.; Zavisova, V.; Koneracka, M.; Kubovcikova, M.; Antal, I.; Kavecansky, V.; Lucanska, D.; Dobrota, D.; Kopcansky, P. Chitosan-stabilized iron oxide nanoparticles for magnetic resonance imaging. J Magn Magn Mater 2019, 474, 319-325, https://doi.org/10.1016/j.jmmm.2018.11.026.

2. Félix, L.L.; Sanz, B.; Sebastián, V.; Torres, T.E.; Sousa, M.H.; Coaquira, J.A.H.; Ibarra, M.R.; Goya, G.F. Gold-decorated magnetic nanoparticles design for hyperthermia applications and as a potential platform for their surface-functionalization. Sci Rep 2019, 9, 1-11, https://doi.org/10.1038/s41598-019-40769-2.

3. Saharkhiz, H.; Gharehaghaji, N.; Nazarpoor, M.; Mesbahi, A.; Pourissa, M. The effect of inversion time on the relationship between iron oxide nanoparticles concentration and signal intensity in T1-weighted MR images. Iran J Radiol 2014, 11, https://doi.org/10.5812/iranjradiol.12667.

4. Taufiq, A.; Nikmah, A.; Hidayat, A.; Sunaryono, S.; Mufti, N.; Hidayat, N.; Susanto, H. Synthesis of magnetite/silica nanocomposites from natural sand to create a drug delivery vehicle. Heliyon 2020, 6 , https://doi.org/10.1016/j.heliyon.2020.e03784.

5. Gharehaghaji, N.; Oghabian, M.A.; Sarkar, S.; Darki, F.; Beitollahi, A. How size evaluation of lymph node is protocol dependent in MRI when using ultrasmall superparamagnetic iron oxide nanoparticles. $J$ Magn Magn Mater 2009, 321, 1563-1565, https://doi.org/10.1016/j.jmmm.2009.02.086.

6. Gharehaghaji, N.; Oghabian, M.A.; Sarkar, S.; Amirmohseni, S.; Ghanaati, H. Optimization of pulse sequences in magnetic resonance lymphography of axillary lymph nodes using magnetic nanoparticles. $J$ Nanosci Nanotechnol 2009, 9, 4448-445,. https://doi.org/10.1166/jnn.2009.M75.

7. Jacques, V.; Dumas, S.; Sun, W.C.; Troughton, J.S.; Greenfield, M.T.; Caravan, P. High relaxivity MRI contrast agents part 2: Optimization of inner-and second-sphere relaxivity. Invest Radiol 2010, 45, 613-624, https://doi.org/10.1097/RLI.0b013e3181ee6a49.

8. Sheng-Nan, S.; Chao, W.; Zan-Zan, Z.; Yang-Long, H.; Venkatraman, S.S.; Zhi-Chuan, X. Magnetic iron oxide nanoparticles: Synthesis and surface coating techniques for biomedical applications. Chin Physics $B$ 2014, 23, https://doi.org/10.1088/1674-1056/23/3/037503.

9. Khatamian, M.; Divband, B.; Farahmand-Zahed, F. Synthesis and characterization of Zinc (II)-loaded Zeolite/Graphene oxide nanocomposite as a new drug carrier. Mater Sci Eng C 2016, 66, 251-8, https://doi.org/10.1016/j.msec.2016.04.090.

10. Divband, B.; Rashidi, M.R.; Khatamian, M.; Eslamian, G.K.; Gharehaghaji, N.; Tabriz, F.D. Linde type A and nano magnetite/NaA zeolites: cytotoxicity and doxorubicin loading efficiency. Open Chem 2018, 16, 21-28, https://doi.org/10.1515/chem-2018-0001.

11. Karimi, M.; Habibizadeh, M.; Rostamizadeh, K.; Khatamian, M.; Divband, B. Preparation and characterization of nanocomposites based on different zeolite frameworks as carriers for anticancer drug: zeolite Y versus ZSM-5. Polym Bull 2019, 76, 2233-2252, https://doi.org/10.1007/s00289-018-2472-1.

12. Ghaderi, S.; Divband, B.; Gharehaghaji, N. Magnetic resonance imaging property of doxorubicin-loaded gadolinium/13X zeolite/folic acid nanocomposite. J Biomed Phys Eng 2020, 10, 103-110, https://doi.org/10.31661/jbpe.v0i0.1254.

13. Gomes, D.S.; Santos, A.M.C.; Neves, G.A.; Menezes, R.R. A brief review on hydroxyapatite production and use in biomedicine. Cerâmica 2019, 65, 282-302, http://dx.doi.org/10.1590/0366-69132019653742706.

14. Pokhrel, S. Hydroxyapatite: preparation, properties and its biomedical applications. Adv Chem Engineer Sci 2018, 8, 225-240, https://doi.org/10.4236/aces.2018.84016.

15. George, S.; Mehta, D.; Saharan, V.K. Application of hydroxyapatite and its modified forms as adsorbents for water defluoridation: an insight into process synthesis. Rev Chem Eng 2020, 36, 369-400, https://doi.org/10.1515/revce-2017-0101.

16. Maity, J.P.; Hsu, C.M.; Lin, T.J.; Lee, W.C.; Bhattacharya, P.; Bundschuh, J.; Chen, C.Y. Removal of fluoride from water through bacterial-surfactin mediated novel hydroxyapatite nanoparticle and its efficiency 
assessment: adsorption isotherm, adsorption kinetic and adsorption thermodynamics. Environ Nanotechnol Monit 2018, 9, 18-28, https://doi.org/10.1016/j.enmm.2017.11.001.

17. Siswanto, S.; Hikmawati, D.; Kulsum, U.; Rudyardjo, D.I.; Apsari, R.; Aminatun, A. Biocompatibility and osteoconductivity of scaffold porous composite collagen-hydroxyapatite based coral for bone regeneration. Open Chem 2020, 18, 584-590, https://doi.org/10.1515/chem-2020-0080.

18. Hokmabad, V. R.; Davaran, S.; Aghazadeh, M.; Alizadeh, E.; Salehi, R.; Ramazani, A. A comparison of the effects of silica and hydroxyapatite nanoparticles on poly ( $\varepsilon$-caprolactone)-poly (ethyleneglycol)-poly ( $\varepsilon$ caprolactone)/chitosan nanofibrous scaffolds for bone tissue engineering. Tissue Eng Regen Med 2018, 15, 735-750, https://doi.org/10.1007/s13770-018-0140-z.

19. Yang, C.; Huan, Z.; Wang, X.; Wu,m C.; Chang, J. 3D printed Fe scaffolds with HA nanocoating for bone regeneration. ACS Biomater Sci Eng 2018, 4, 608-616, https://doi.org/10.1021/acsbiomaterials.7b00885.

20. Arcos, D.; Vallet-Regí, M. Substituted hydroxyapatite coatings of bone implants. J Mater Chem B 2020, 8 , 1781-1800, https://doi.org/10.1039/c9tb02710f.

21. Odusote, J.K.; Danyuo, Y.; Baruwa, A.D.; Azeez, A.A. Synthesis and characterization of hydroxyapatite from bovine bone for production of dental implants. J Appl Biomater Func Mater 2019, 17, https://doi.org/10.1177/2280800019836829.

22. Kundu, B.; Sinha, M.K.; Mitra, S.; Basu, D. Synthetic hydroxyapatite-based integrated orbital implants: a human pilot trial. Indian J Ophthalmol 2005, 53, 235-241, https://doi.org/10.4103/0301-4738.18904.

23. Lamkhao, S.; Phaya, M.; Jansakun, C.; Chandet, N.; Thongkorn, K.; Rujijanagul, G.; Bangrak, P.; Randorn, C. Synthesis of hydroxyapatite with antibacterial properties using a microwave-assisted combustion method. Sci Rep 2019, 9, 1-9, https://doi.org/10.1038/s41598-019-40488-8.

24. Eslami, H.; Tahriri, M.; Moztarzadeh, F.; Bader, R.; Tayebi, L. Nanostructured hydroxyapatite for biomedical applications: from powder to bioceramic. J Korean Ceram Soc 2018, 55, 597-607, https://doi.org/10.4191/kcers.2018.55.6.10.

25. Suresh Kumar, C.; Dhanaraj, K.; Vimalathithan, R.M.; Ilaiyaraja, P.; Suresh, G. Hydroxyapatite for bone related applications derived from sea shell waste by simpleprecipitation method. J Asian Ceram Soc 2020, 8, 416-429, https://doi.org/10.1080/21870764.2020.1749373.

26. Zheltova, V.; Vlasova, A.; Bobrysheva, N.; Abdullin, I.; Semenov, V.; Osmolowsky, M.; Voznesenskiy, M.; Osmolovskaya, O. $\mathrm{Fe}_{3} \mathrm{O}_{4} @$ HAp core-shell nanoparticles as MRI contrast agent: synthesis, characterization and theoretical and experimental study of shell impact on magnetic properties. Appl Surf Sci 2020, 531, https://doi.org/10.1016/j.apsusc.2020.147352.

27. Pu'ad, N.M.; Koshy, P.; Abdullah, H.Z.; Idris, M.I.; Lee, T.C. Syntheses of hydroxyapatite from natural sources. Heliyon 2019, 5, e01588. https://doi.org/10.1016/j.heliyon.2019.e01588.

28. Jaber, H.L.; Hammood, A.S.; Parvin, N. Synthesis and characterization of hydroxyapatite powder from natural Camelus bone. J Aust Ceram Soc 2018, 54, 1-10, https://doi.org/10.1007/s41779-017-0120-0.

29. Teymouri A.; Stuart, B.J.; Kumar S. Hydroxyapatite and dittmarite precipitation from algae hydrolysate, Algal Res 2018, 29, 202-211, https://doi.org/10.1016/j.algal.2017.11.030.

30. Laranjeira, M.S.; Moco, A.; Ferreira, J.; Coimbra, S.; Costa, E.; Santos-Silva, A.; Ferreira, P.J.; Monteiro, F.J. Different hydroxyapatite magnetic nanoparticles for medical imaging: Its effects on hemostatic, hemolytic activity and cellular cytotoxicity. Colloids Surf B: Biointerfaces 2016, 146, 363-374, http://dx.doi.org/10.1016/j.colsurfb.2016.06.042.

31. Mondal, S.; Manivasagan, P.; Bharathiraja, S.; Moorthy, M.S.; Kim, H.H.; Seo, H.; Lee, K.D.; Oh, J. Magnetic hydroxyapatite: a promising multifunctional platform for nanomedicine application. Int $J$ Nanomedicine 2017, 12, 8389-8410, https://doi.org/10.2147/IJN.S147355.

32. Sneha, M.; Sundaram, N.M. Preparation and characterization of an iron oxide-hydroxyapatite nanocomposite for potential bone cancer therapy. Int $J$ Nanomedicine 2015, 10, 99-106. https://doi.org/10.2147/IJN.S79985.

33. Wu, H.C.; Wang, T.W.; Lin, F.H.; Sun, J.S. Characterization of magnetic hydroxyapatite nanocrystallites and potential application for MRI contrast agent. Curr Nanosci 2011, 7, 902-907, https://doi.org/10.2174/157341311798220754.

34. Chang, K.C.; Li, C.Y.; Hsu, C.K.; Kuo, M.S. Synthesis and properties of Fe-modified calcium-deficient hydroxyapatite nanocrystal for MRI contrast agent. Biomedl Eng: Appl Basis Commun 2011, 23, 393-401, https://doi.org/10.4015/S1016237211002724.

35. Kermanian, M.; Naghibi, M.; Sadighian, S. One-pot hydrothermal synthesis of a magnetic hydroxyapatite nanocomposite for MR imaging and $\mathrm{pH}$-Sensitive drug delivery applications. Heliyon 2020, 6, https://doi.org/10.1016/j.heliyon.2020.e04928.

36. Yusoff, A.H.M.; Salimi, M.N.; Jamlos M.F. Synthesis of superparamagnetic hydroxyapatite core-shell nanostructure by a rapid sol-gel route. E-J Surf Sci Nanotechnol 2017, 15, 121-126, https://doi.org/10.1380/ejssnt.2017.121.

37. Arsalani, N.; Fattahi, H.; Nazarpoor, M. Synthesis and characterization of PVP-functionalized superparamagnetic Fe3O4 nanoparticles as an MRI contrast agent. Express Polym Lett 2010, 4, 329-338, https://doi.org/10.3144/expresspolymlett.2010.42. 
38. Zhou, Z.; Zhao, Z.; Zhang, H.; Wang, Z.; Chen, X.; Wang, R.; Chen, Z.; Gao, J. Interplay between longitudinal and transverse contrasts in $\mathrm{Fe} 3 \mathrm{O} 4$ nanoplates with (111) exposed surfaces. ACS Nano 2014, 8, 7976-7985, https://doi.org/10.1021/nn5038652.

39. Keshtkar, M.; Shahbazi-Gahrouei, D.; Mahmoudabadi, A. Synthesis and application of $\mathrm{Fe}_{3} \mathrm{O}_{4} @ \mathrm{Au}$ composite nanoparticles as magnetic resonance/computed tomography dual-modality contrast agent. J Med Signals Sens 2020, 10, 201-207, https://doi.org/10.4103/jmss.JMSS_55_19. 